\title{
Design of smart wireless changeover for continuous electric current feeding from power sources of variable capacities
}

\author{
Haider A. H. Alobaidy ${ }^{1}$, Hikmat N. Abdullah ${ }^{2}$, Tariq M. Salman ${ }^{3}$ \\ ${ }^{1}$ Department of Electrical, Electronic and Systems Engineering, Faculty of Engineering and Built Environment, \\ Universiti Kebangsaan Malaysia, Malaysia \\ ${ }^{2}$ College of Information Engineering, Al-Nahrain University, Iraq \\ ${ }^{3}$ Electrical Engineering Department, Faculty of Engineering, Al-Mustansiriya University, Iraq
}

\begin{tabular}{l}
\hline Article Info \\
\hline Article history: \\
Received Mar 22, 2019 \\
Revised Jan 14, 2020 \\
Accepted Feb 1, 2020 \\
\hline
\end{tabular}

Keywords:

Automation

IEEE 802.15.4

Monitoring

Smart wireless changeover

Wireless sensor network (WSN)

ZigBee

\begin{abstract}
Electric power has become a vital element for life today. Despite this importance, electric power consumers in Iraq suffer from the problem of noncontinuity and daily electric power supply interruption. This problem led to the use of various sources of electric power as an alternative to compensate for the shortage of electric power provided by the Iraqi national grid. In this work, a smart wireless changeover device is designed using wireless sensor networks technology aiming to solve problem caused by the multiplicity of power sources received at home and governmental buildings in Iraq by controlling operation of some electrical devices (which consume high current) in the home or workplace automatically when changing source of electricity from one to another. This solution will help to ensure the continuity of electric current feeding from power sources of variable capacities, also, to rationalize power consumption by assigning an operation priority to electric devices. Furthermore, a statistical measurement as a case study was performed in a building with a total power consumption of $160.8 \mathrm{KW} / \mathrm{h}$. The result showed that the device functions effectively and it is capable of achieving an average saving in power of about $50 \%$ to $86 \%$ depending on the applied priorities and case study scenario.
\end{abstract}

Copyright $(02020$ Institute of Advanced Engineering and Science. All rights reserved.

\section{Corresponding Author:}

Haider A. H. Alobaidy,

Department of Electrical, Electronic and Systems Engineering,

Faculty of Engineering and Built Environment,

Universiti Kebangsaan Malaysia,

UKM Bangi, Selangor 43600, Malaysia.

Email: p92976@siswa.ukm.edu.my

\section{INTRODUCTION}

In recent years, the field of wireless sensor networks has evolved rapidly and signaled a promising turnaround in people life and business as there are many applications in this field, particularly for applications and systems to monitor power consumption, and for medical and military applications [1-6]. Nowadays, electric power is one of the essential elements of life. Despite the availability of multiple sources of power generation, its availability has become expensive in the world in general and in Iraq in particular [7-10]. For this reason, energy research focuses on finding solutions to rationalize and sustain power consumption [11-14]. There are several attempts to employ wireless sensor networks to conserve electricity $[1,11,15-23]$. These attempts vary in their objectives. Some used these networks to monitor, visualize power consumption, and to warn consumers when usage exceeds consumer's predefined limit. Others used the technology for switching electrical devices on and off by sending commands wirelessly via a mobile phone application predefined limit of the consumer. Another attempts employed the technology to manually turn off electric devices and monitor the consumption by sending commands wirelessly through 
a mobile phone application. However, those contributions did not solve the crux of the problem caused due to the change of electric power supplied to a home or workplace to another power source with limited power capacity. The current work addresses this problem as it allows the consumer to control the operation of the devices according to the type of the electric power source being supplied.

Consumers of electric power in Iraq suffer continuously during the whole day from the problem of non-continuity and interruption of electric power $[10,24,25]$. This problem led to the use of several electric power sources as an alternative source to compensate for the lack of electric power provided by the Iraqi national grid. However, these sources are limited according to consumer needs and financial ability. Due to the multiplicity of power sources received at home, government departments and factories in Iraq and the amount of electricity consumed from each of these sources, it is necessary to control the operation of some devices in the house and the workplace automatically when the source of power changes from one to another. For example, when it changes from the national network power source to the private sector power generator or vice versa. Some high-current devices such as air conditioners and heaters cannot be operated on low power sources and small generators, which must be switched off manually. Additionally, there are usually major electrical problems that cause damage to the devices or power cables. This is because when these devices are kept on while changing the power source to the private generator and the supplied power is repeatedly interrupted by the power breaker when exceeding the breaker current limit.

In this work, a proposed device is designed aiming to wirelessly control the operation of electrical devices, according to the user's needs, by using a microcontroller with a wireless sensor network. The proposed smart wireless changeover device is designed to solve previously mentioned problems and thus avoid manually turning off or on devices when switching sources of electrical power. This feature helps to ensure the continuity of electric current feeding from power sources of variable capacities to homes and workstations as well as saving the costs of re-assignment of power lines in buildings according to the supplied source. Furthermore, the proposed device also helps in rationalizing power consumption by assigning an operation priority to electric devices. The core components of this work include an Arduino microcontroller, an XBee ZigBee wireless transceiver, a Current Transformer CT, and a low or high-power protection device.

The rest of this paper is organized as follows. The next section describes the proposed device components and overall structure. Section 3 describes the proposed device functionality and operation mechanism. Section 4, discuss the performance and testing results. Finally, some conclusions and suggestions are drawn in section 5 and 6.

\section{THE PROPOSED DEVICE DESCRIPTION}

The proposed device consists of two main parts: the central control unit or Base Station (BS) and the terminal control unit or End Node (EN). The BS is responsible for the sensitivity of the incoming currents to the home or workplace and the source of these currents. This unit consists of an Arduino Mega microcontroller which is responsible for controlling the system by programming it according to user needs. The unit also contains three current sensors (CT) to determine the source of electric current entering the home or workplace, i.e., the source of the national network, private sector generator, or household generator. Figure 1 shows the components of the BS. The signal is transferred to and from the central control unit using the transceiver XBee ZigBee. As for the EN, it receives the signal from the BS. According to the user's choice, which is determined by the selector in this unit. The Arduino Mini microcontroller determines the operation of the electrical device connected to the EN. For example, working on the national network electric current source only. Figure 2 shows the components of the EN.

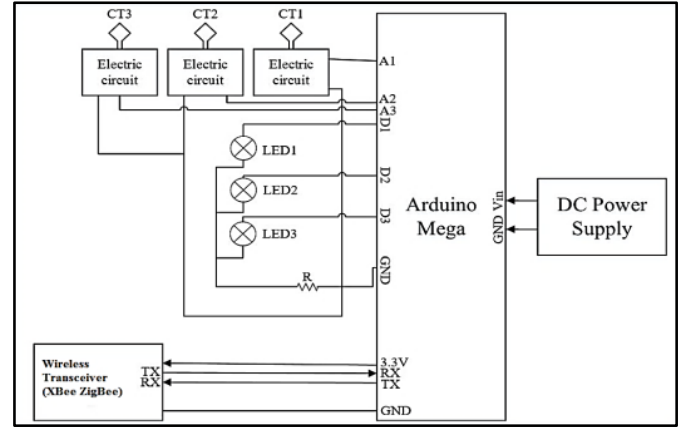

Figure 1. Base station (BS) infrastructure

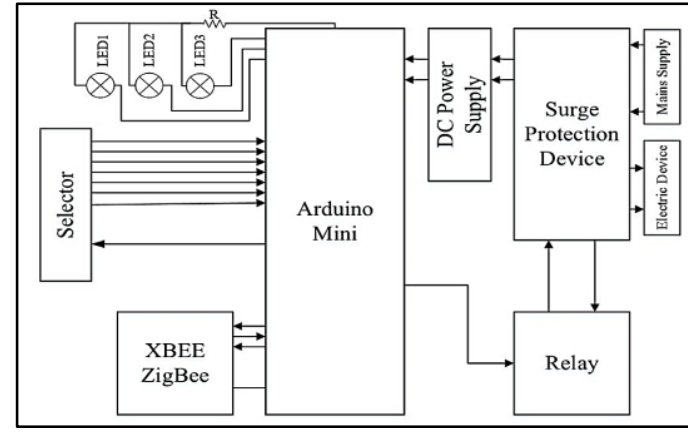

Figure 2. End node (EN) infrastructure 


\section{THE SYNTHESIS OF THE SMART CHANGEOVER}

Figures 3-5 illustrate the stages of building the prototype of the proposed device for both the BS and the EN as well as showing the system functionality. The designed system works in the following sequence and as shown in Figure 6 and Figure 7:

a. The microcontroller in the BS monitors or senses the voltage on the three main current sensors connected to the BS (CT1, CT2, and CT3). If the sensed electric current is fed from the national network (for example), the controller will turn on LED1 referring to the current of the national network and sends a unique code via the ZigBee to the other ENs in the system to make the appropriate decision according to the choice of the EN user.

b. At the EN, the user selects on which current source the electrical device connected to this unit needs to operate through a selector, i.e., whether it needs to be operating on the national network only, or on the private sector generator only, or on the household generator only, or on the national network and the private sector generator together, etc. Note that the user selects the electric current source to operate the EN on it only once and for each EN device in the system network.

c. Then, the EN microcontroller waits for a signal from the BS. Once the signal is received by ZigBee of the EN, the microcontroller (Arduino Micro) sends a signal to the relay connected to the microcontroller and thus the surge protection device is supplied with electric power. Finally, the surge protection device will supply the connected device (the load) with electric current if the supplied electric power is stable, otherwise (when there the current is fluctuated to higher or lower than the rated voltage) it will cutoff the supply and wait until reaching the stabilization state.

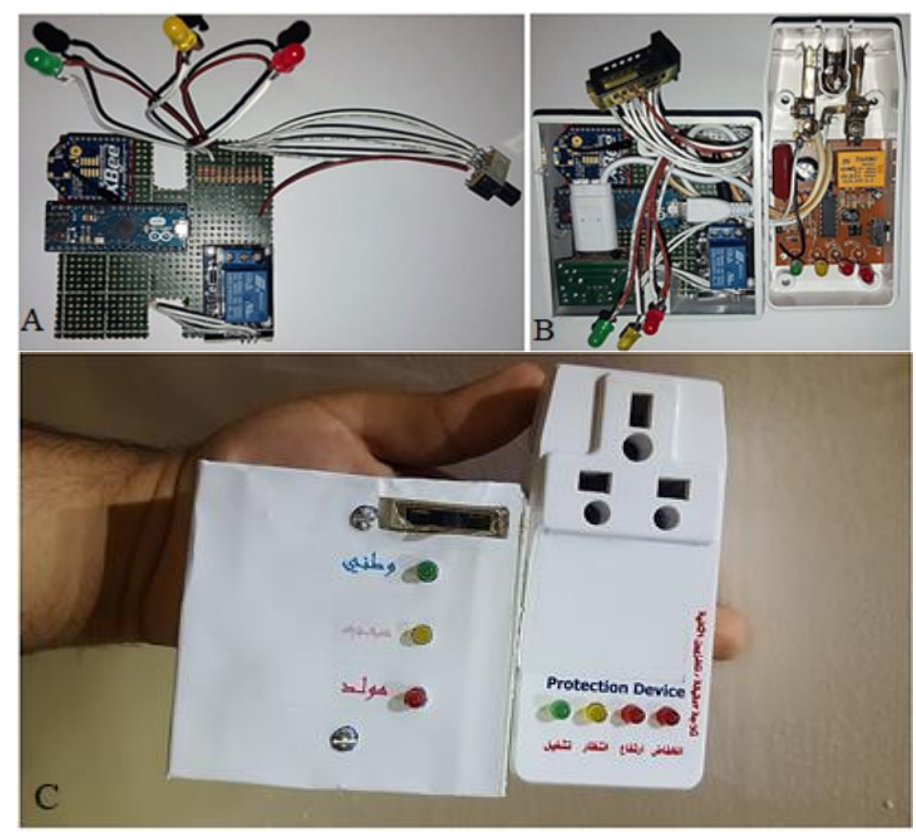

Figure 3. Implementation stages of EN.

(a) microcontroller, transceiver, relay, and EN switch, which represents the control unit, data receiving and transmitting, and managing EN functions, (b) Assembly of EN parts, (c) EN after assembly

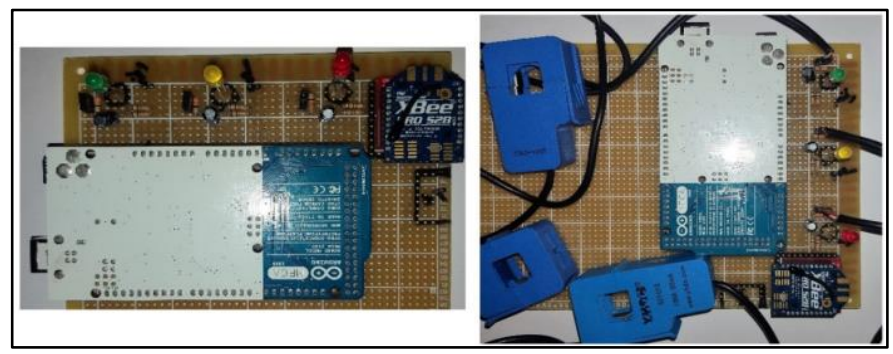

Figure 4. The stages of building the central unit 


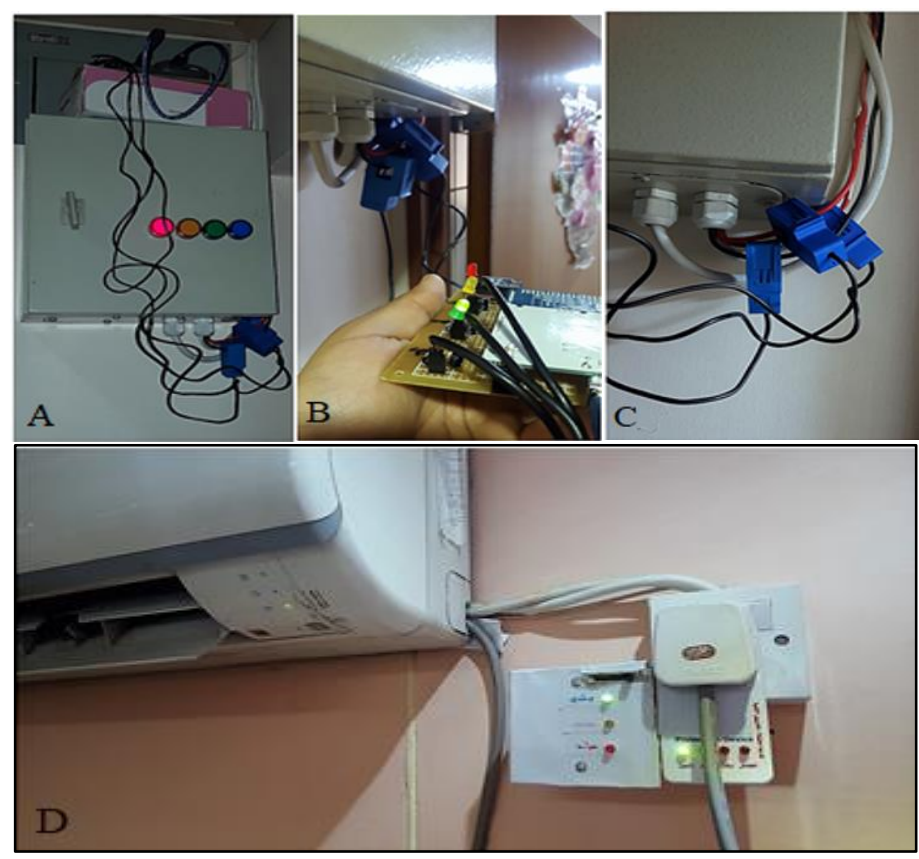

Figure 1. Clarification of the EN and BS function, (a) The BS is connected to the power supply lines, (b) The BS is active and the green light is illuminated which indicates sensitivity to the current of the national grid. (c) The CT sensors are connected to the power supply lines. (d) The EN is active and supplying electric current to the air conditioner

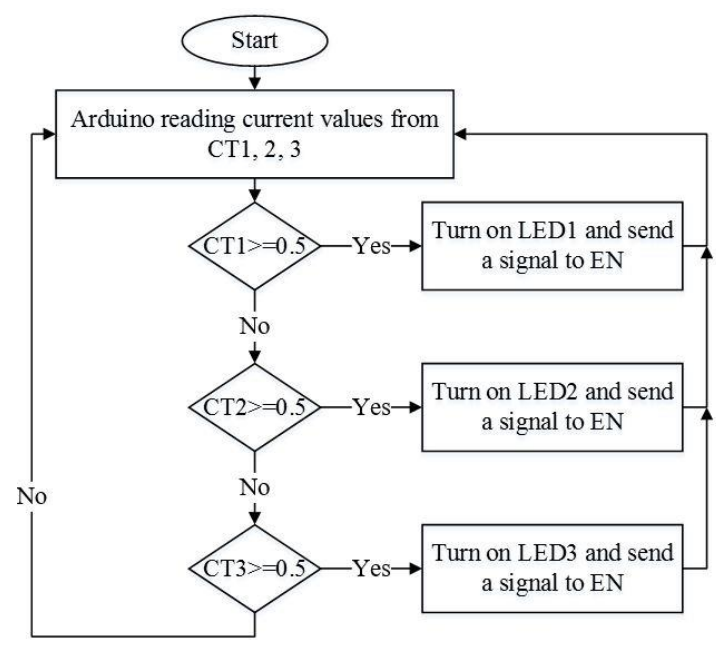

Figure 6. Operation mechanism of the BS

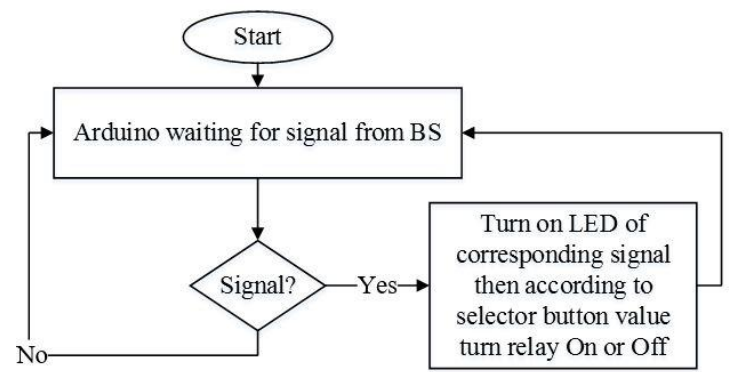

Figure 7. Operation mechanism of the EN 


\section{TESTING RESULTS}

The device is mainly designed to control the operation of some electrical appliances (which consume high current) in the home or workplace automatically when changing the source of electricity to ensure the continuity of electric current feeding from the power source. This feature can also help to rationalize power consumption by assigning an operation priority to electric devices. To demonstrate the power saving capability of the designed device, a statistical measurement as a case study was performed at the building of the Electrical Engineering Department/ College of Engineering/ Al Mustansiriya University located in Baghdad. The study considered a number of air conditioning devices in each room of the building. Each device was assigned to a specific priority $(1,2$, or 3 ) within the room according to the necessity of that device and how it may operate. This assumption showed that there would be different power saving capabilities depending on the intended operating scenario that can be specified through the proposed device. Table 1 shows the number of high current electric loads, their average consumption, and the assigned priority for each lecturers' rooms, classrooms, offices, and laboratories. It can be seen from the table that the total consumed power in the building is $160.8 \mathrm{KW} / \mathrm{h}$.

Many scenarios were considered depending on the yearly operation of the electric loads in the building. These scenarios are:

1. Normal working days scenario.

2. Exam scenario.

3. Summer and spring holiday's scenario.

4. Winter working days scenario.

5. Secondary schools final exam scenario.

In normal working days scenario, all loads in the building are usually turned on, and there will be no saving in power as can be seen in Figure 8. However, by using the proposed device the saving in power varies depending on the selected priority of operation which can be seen clearly in the figure. In Exam scenario, some of the devices are usually turned on so in this case there will be a usual saving of about $67 \%$. Applying priorities using the proposed device will help in reducing the consumption further as can be seen in Figure 9. Applying the same criteria for other scenarios will provide different power saving capabilities, as can be seen in Figures 10-12, for the Summer and Spring holidays scenario, Winter working days scenario, and secondary schools final exams scenario respectively.

The device has been tested practically and proved to be successful in controlling the operation of electrical devices according to the needs of the user. Figure 5(a) shows the BS attached to the electrical power supply lines. Figure 5(b) shows the BS active and the green light is illuminating indicating that the BS has sensed the presence of the national grid electric current. According to its programming, the BS will send instructions to the ENs to operate the connected devices if the user had chosen to operate them on the national network only (for example) which can be seen in Figure 5(d). The specific case in this figure shows the EN operating and supplying electric current to an air conditioner.

Furthermore, as shown in section 4 the power saving capability of the device is studied and proved to be very effective. According to the study, there has been an average saving in power of about $50 \%$ to $86 \%$ depending on the applied priorities and case study scenario. This can be seen clearly in Figure 13 where the minimum, average, and maximum power saving capability for all case studies are given.

Table 1. The number of high current electric loads, their average consumption,

\begin{tabular}{cccccccc}
\multicolumn{7}{c}{ and the assigned priority for each load in the building } \\
\hline Room No. & No. of Loads & Priority & Amp/h & Room No. & No. of Loads & Priority & Amp/h \\
\hline 1 & 2 & 1 & 40 & 19 & 2 & 3 & 20 \\
2 & 2 & 1 & 20 & 20 & 2 & 1 & 20 \\
3 & 1 & 2 & 10 & 21 & 1 & 3 & 10 \\
4 & 2 & 3 & 20 & 22 & 1 & 3 & 10 \\
5 & 3 & 2 & 30 & 23 & 1 & 3 & 10 \\
6 & 3 & 2 & 30 & 24 & 1 & 3 & 10 \\
7 & 3 & 2 & 30 & 25 & 1 & 3 & 10 \\
8 & 3 & 2 & 30 & 26 & 1 & 3 & 10 \\
9 & 3 & 2 & 30 & 27 & 1 & 3 & 10 \\
10 & 3 & 2 & 30 & 28 & 1 & 3 & 10 \\
11 & 3 & 2 & 30 & 29 & 1 & 3 & 10 \\
12 & 4 & 2 & 40 & 30 & 1 & 3 & 10 \\
13 & 2 & 2 & 20 & 31 & 1 & 3 & 10 \\
14 & 2 & 2 & 20 & 32 & 1 & 3 & 10 \\
15 & 2 & 3 & 20 & 33 & 1 & 10 & 3 \\
16 & 3 & 1 & 30 & 34 & 1 & 10 & 3 \\
17 & 2 & 1 & 30 & 35 & & 1 & 3 \\
18 & 2 & 1 & 20 & & & & \\
\hline
\end{tabular}

Int J Elec \& Comp Eng, Vol. 10, No. 4, August 2020 : 3460 - 3467 


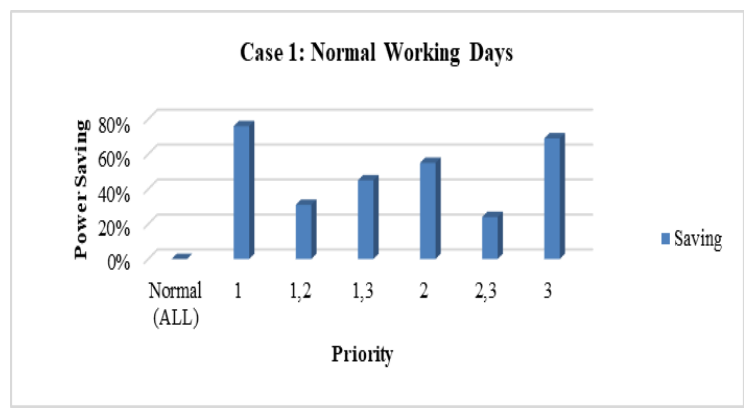

Figure 2. Power saving for different priorities in normal working days scenario

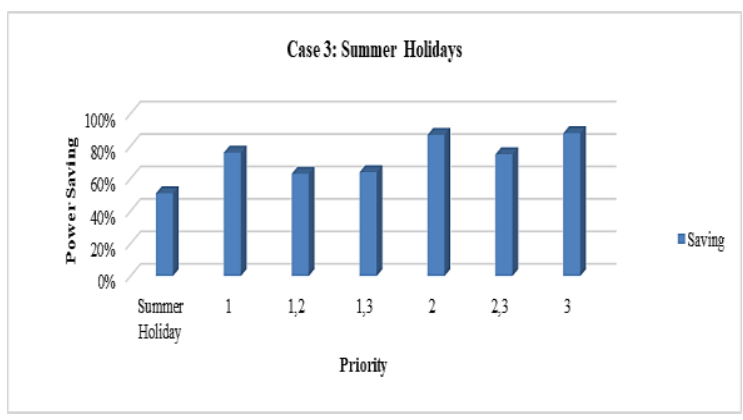

Figure 4. Power saving for different priorities in summer and spring holiday's scenario

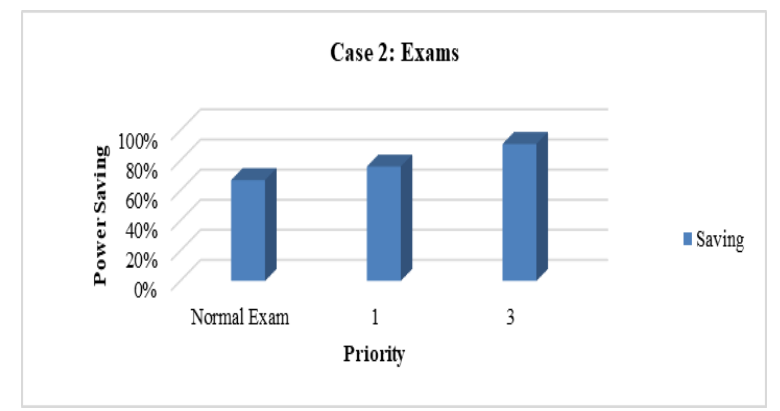

Figure 3. Power saving for different priorities in exam scenario

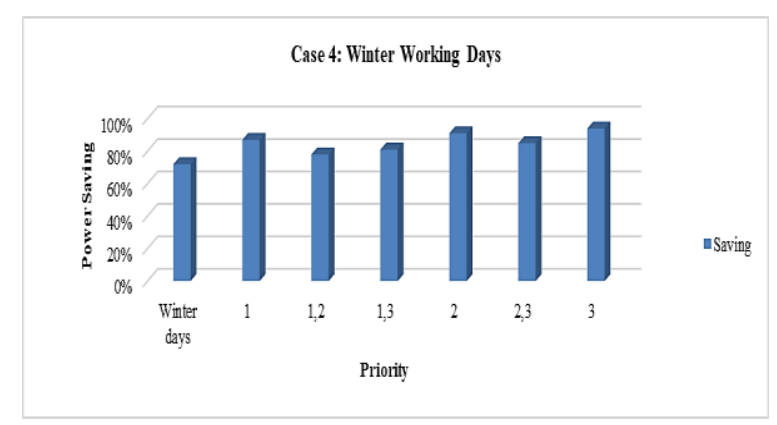

Figure 5. Power saving for different priorities in winter working days scenario

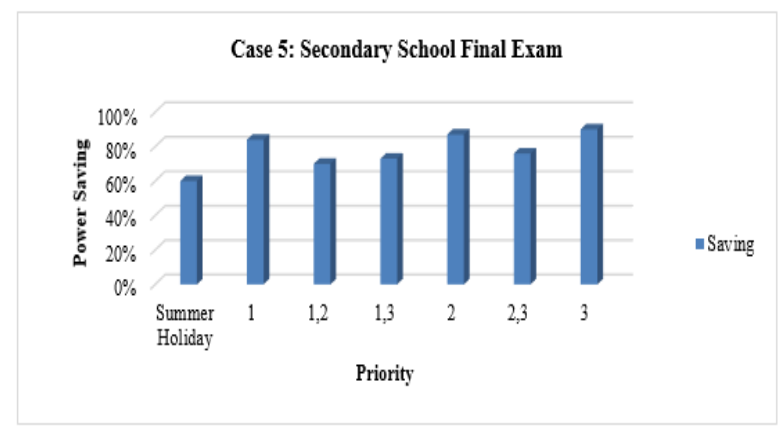

Figure 6. Power saving for different priorities in secondary schools final exam scenario

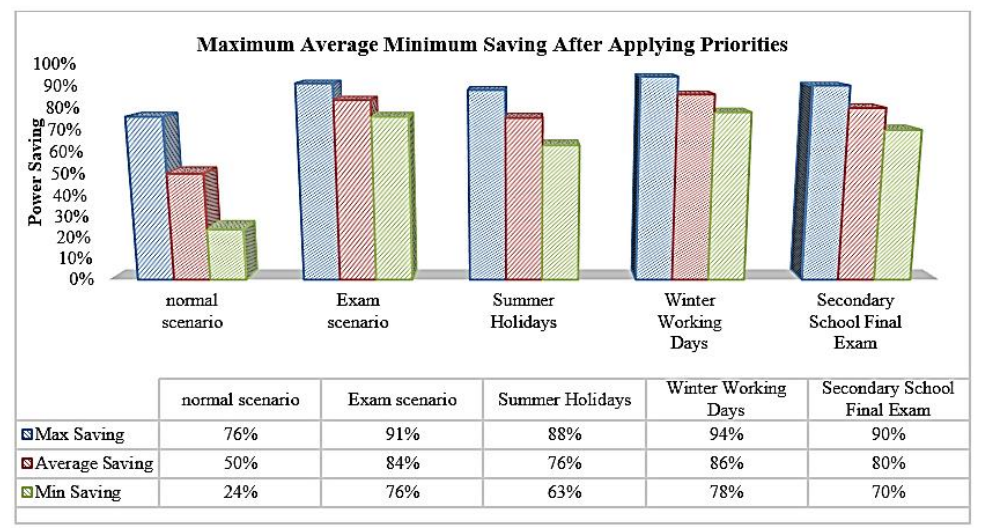

Figure 7. Maximum, average, and minimum power saving capability of the device after applying operating priorities for devices in the building 


\section{CONCLUSION}

In this work, a smart wireless changeover device is designed using wireless sensor networks technology aiming to solve the problem caused by the multiplicity of power sources supplying homes and governmental buildings in Iraq by controlling the operation of some electrical devices (which consume high current) automatically when changing the source of electricity from one to another. According to device performance evaluation results it is concluded that the device helps to ensure the continuity of electric current feeding from power sources of variable capacities as well as saving power. Hence, the results also showed that the device function effectively and is capable of achieving an average saving in power consumption of about $50 \%$ to $86 \%$ depending on the applied priorities and case study scenario (in a building with total power consumption of $160.8 \mathrm{KW} / \mathrm{h}$ ).

Furthermore, the device has multiple features which makes it different and unique. These features can be summarized as follows: it provides the efforts and costs required to re-organize the electric power lines according to the power source, it enables monitoring the operation of electrical devices and the amount of consumption of electric power wirelessly, it is easy in moving and installation inside the buildings (Portable), and it can be developed easily to enable multiple tasks and additional functions.

\section{FUTURE WORK}

Considering the device features and achieved results, many enhancements can be done to the infrastructure of the proposed device to enable additional functions. All that being said, future work can involve some of the following suggestions: (a) Developing the device to perform multiple tasks such as turning off and on the EN electric devices through a mobile phone application which allows the monitoring of the activity of these devices in the workplace as well as the ability to control them from anywhere through the Internet. (b) Adding other sensors such as motion and heat sensors. The addition of such sensors helps to rationalize consumption by monitoring the movement in a place and thus control the operation of lighting in these places for a certain time according to movement. Heat sensors also help to determine the working times of air conditioners according to the room temperature set by the user. (c) Creating a PC and mobile application to control the devices within the proposed device network as well as viewing and receiving notifications about the consumption.

\section{ACKNOWLEDGEMENTS}

The authors would like to thank the Electrical Engineering Department, Faculty of Engineering, Al-Mustansiriyah University, Iraq for providing the required statistical details to accomplish the work. Also, we are grateful for the feedback received on an early version of this work from the Industrial Property Department, Central Organization for Standardization \& Quality Control (COSQC), Ministry of Planning, Iraq which resulted in accepting the work as a patent in Iraq numbered 5261 and dated 26/2/2018.

\section{REFERENCES}

[1] Haider A. H. Alobaidy, "Robust Wireless Sensor Network for Energy Monitoring," M.Sc. Thesis, AL-Mustansiriya University, 2015.

[2] J. H. Kleinschmidt, "Analyzing and improving the energy efficiency of IEEE 802.15 .4 wireless sensor networks using retransmissions and custom coding," Telecommun. Syst., vol. 53, no. 2, pp. 239-245, Jun. 2013.

[3] V. Nithya, B. Ramachandran, and V. Bhaskar, "Energy Efficient Coded Communication for IEEE 802.15.4 Compliant Wireless Sensor Networks," Wirel. Pers. Commun., vol. 77, no. 1, pp. 675-690, Jul. 2014.

[4] B. Rashid and M. H. Rehmani, "Applications of wireless sensor networks for urban areas: A survey," J. Netw. Comput. Appl., vol. 60, pp. 192-219, Jan. 2016.

[5] N. A. A. Rahman and A. B. Jambek, "Biomedical health monitoring system design and analysis," Indonesian Journal of Electrical Engineering and Computer Science (IJEECS), vol. 13, no. 3, pp. 1056-1064, 2019.

[6] J. Zhang, "Application of remote monitoring and management of high-speed rail transportation based on ZigBee sensor network," EURASIP J. Wirel. Commun. Netw., vol. 40, no. 2019, 2019.

[7] A. R. Jordehi, "Optimisation of demand response in electric power systems, a review," Renew. Sustain. Energy Rev., vol. 103, pp. 308-319, Apr. 2019.

[8] I. Topcu, F. Ülengin, Ö. Kabak, M. Isik, B. Unver, and S. Onsel Ekici, "The evaluation of electricity generation resources: The case of Turkey,” Energy, vol. 167, pp. 417-427, Jan. 2019.

[9] N. A. Mohammed, "Modelling of unsuppressed electrical demand forecasting in Iraq for long term," Energy, vol. 162, pp. 354-363, Nov. 2018.

[10] H. M. Almukhtar, et al., "Feasibility study of achieving reliable electricity supply using hybrid power system for rural primary schools in Iraq: A case study with Umm Qasr primary school," International Journal of Electrical and Computer Engineering (IJECE), vol. 9, no. 4, pp. 2822-2830, 2019. 
[11] H. N. Abdullah, T. M. Salman, and H. A. H. Alobaidy, "Design of a ZigBee based WSN with channel coding for energy and temperature monitoring," in 2016 Al-Sadeq International Conference on Multidisciplinary in IT and Communication Science and Applications (AIC-MITCSA), pp. 1-5, 2016.

[12] C. Cañizares, J. Nathwani, and D. Kammen, "Electricity for All: Issues, Challenges, and Solutions for EnergyDisadvantaged Communities," Proc. IEEE, vol. 107, no. 9, pp. 1775-1779, 2019.

[13] P. Bertheau, "Assessing the impact of renewable energy on local development and the Sustainable Development Goals: Insights from a small Philippine island," Technol. Forecast. Soc. Chang., vol. 153, no. April 2020, pp. 119919, 2020.

[14] R. N. Dar-Mousa and Z. Makhamreh, "Analysis of the pattern of energy consumptions and its impact on urban environmental sustainability in Jordan: Amman City as a case study," Energy. Sustain. Soc., vol. 9, no. 15, 2019.

[15] A. González-Briones, J. Prieto, F. De La Prieta, E. Herrera-Viedma, and J. M. Corchado, "Energy optimization using a case-based reasoning strategy," Sensors (Switzerland), vol. 18, no. 3, pp. 1-27, 2018.

[16] H. A. H. Alobaidy, H. N. Abdullah, and T. M. Salman, "Implementation and Performance Evaluation of WSN for Energy Monitoring Application,” Eng. \& Tech. Journal, vol. 33, no. 7, pp. 1555-1568, 2015.

[17] T. Nozawa and M. Inoue, "Smart Outlet for realizing secure and green living," in 2011 IEEE 15th International Symposium on Consumer Electronics (ISCE), pp. 432-437, 2011.

[18] S.C. Peng, L.S. Dai, T.H. Su, "The design of smart electrical outlet for Smart Home base on power line communication," in 2014 International Conference on Intelligent Green Building and Smart Grid (IGBSG), pp. 1-4, 2014.

[19] A. A. Valenzuela, "Multisensor system for energy consumption awareness in large buildings," in 2012 International Conference on Smart Grid Technology, Economics and Policies (SG-TEP), pp. 1-4, 2012.

[20] M. Chincoli, A. A. Syed, G. Exarchakos, and A. Liotta, "Power Control in Wireless Sensor Networks with Variable Interference," Mob. Inf. Syst., vol. 2016, pp. 1-10, 2016.

[21] Ó. Blanco-Novoa, T. Fernández-Caramés, P. Fraga-Lamas, and L. Castedo, "An Electricity Price-Aware OpenSource Smart Socket for the Internet of Energy," Sensors, vol. 17, no. 3, pp. 643, Mar. 2017.

[22] L. Angrisani, F. Bonavolontà, A. Liccardo, R. S. Lo Moriello, and F. Serino, "Smart Power Meters in Augmented Reality Environment for Electricity Consumption Awareness," Energies, vol. 11, no. 9, pp. 2303, 2018.

[23] I. M. Nayyef and A. A. Hussien, "Intelligent power monitoring and control with wireless sensor network techniques," Indonesian Journal of Electrical Engineering and Computer Science (IJEECS), vol. 18, no. 2, pp. 1113-1122, 2020.

[24] J. A. Mohammed, et al., "Voltage disturbance mitigation in Iraq's low voltage distribution system," Indonesian Journal of Electrical Engineering and Computer Science (IJEECS), vol. 17, no. 1, pp. 47-60, 2020.

[25] F. A. Lattieff, M. A. Atiya, and A. A. Al-hemiri, "Test of solar adsorption air-conditioning powered by evacuated tube collectors under the climatic conditions of Iraq," Renew. Energy, vol. 142, pp. 20-29, 2019.

\section{BIOGRAPHIES OF AUTHORS}
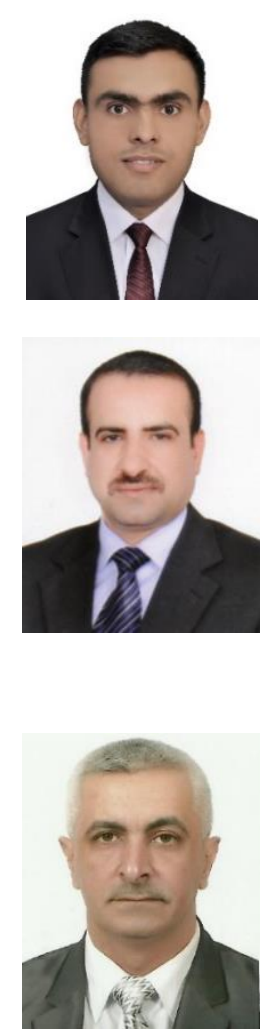

Haider A. H. Alobaidy was born in Iraq in 1991. He received the M.Sc. degree in Electrical Engineering/ Electronic \& Communication from the Faculty of Engineering, Al-Mustansiriyah University, Iraq in 2016. He is currently a Ph.D. student in the Department of Electrical, Electronic \& Systems Engineering, Faculty of Engineering and Built Environment, Universiti Kebangsaan Malaysia (UKM). His research interest includes wireless sensor networks, wireless communication, IoT, and channel propagation modeling and estimation.

Hikmat. N. Abdullah was born in Baghdad, Iraq in 1974. He obtained his B.Sc. in Electrical Engineering in 1995, M.Sc. in Communication Engineering in 1998 at Al-Mustansiriyah University, Iraq and Ph.D. in Communication Engineering in 2004 at University of Technology, Iraq. From 1998 to 2015 he worked as a lecturer in the Electrical Engineering Department, at Al-Mustansiriyah University., Iraq. Since the beginning of 2015, he works as a professor in the College of Information Engineering at Al-Nahrain University, Iraq. From 2011-2013 he got a research award from International Institute of Education (IIE/USA) at Bonn-Rhein-Sieg University of Applied Sciences, Germany. He is a senior member of the IEEE association since 2014. He is interested in the subject of modulation and coding schemes for wireless communication systems.

Tariq M. Salman was born in Baghdad, Iraq in 1972. He obtained his B.Sc. in Electrical Engineering in 1995, M.Sc. in Communication Engineering in 2003 at University of Technology, Iraq and Ph.D. in Telecommunication and Network devices in 2012 at Belarussian State University of Informatics and Radio Electronics, Belarus. From 2006 to 2012 he worked as a lecturer in the Electrical Engineering Faculty, at Al-Mustansiriyah University, Iraq. Since the beginning of 2018, he works as an assistant professor in the same Faculty. He is a consultant member of the Iraqi Engineering union since 2013. He is interested in the subject of wireless and network devices, video and image processing systems. 